\title{
Antenatal screening for aneuploidy
}

\author{
Smita S. Patne ${ }^{1}$, Aditi J. Upadhye ${ }^{2}$, Shantanu C. Shembekar ${ }^{3}$, \\ Chaitanya A. Shembekar ${ }^{4}$, Jayshree J. Upadhye ${ }^{5 *}$
}

\author{
${ }^{1}$ Department of Obstetrics and Gynecology, Patne Hospital and Maternity Home, Aurangabad, Maharashtra, India \\ ${ }^{2}$ Medical student, PDMMC, Amravati, Maharashtra, India \\ ${ }^{3}$ Medical student, GMC, Nagpur, Maharashtra, India \\ ${ }^{4}$ Department of Obstetrics and Gynecology, Omega Hospital, Nagpur, Maharashtra, India \\ ${ }^{5}$ Department of Obstetrics and Gynecology, UCH Hospital, Nagpur, Maharashtra, India
}

Received: 08 November 2017

Accepted: 02 December 2017

\section{*Correspondence:}

Dr. Jayshree J. Upadhye,

E-mail: jayshreeupadhye@gmail.com

Copyright: (C) the author(s), publisher and licensee Medip Academy. This is an open-access article distributed under the terms of the Creative Commons Attribution Non-Commercial License, which permits unrestricted non-commercial use, distribution, and reproduction in any medium, provided the original work is properly cited .

\begin{abstract}
Background: It is uncertain how best to screen pregnant women for the presence of fetal Down's syndrome and other aneuploides, whether to perform first-trimester screening or to perform second-trimester screening or both.

Methods: Women with singleton and multiple pregnancies underwent first-trimester combined screening (measurement of nuchal translucency, pregnancy-associated plasma protein A [PAPP-A], and the free beta subunit of human chorionic gonadotropin at 10 weeks 3 days through 13 weeks 6 days of gestation). Also, second-trimester quadruple screening (measurement of alpha-fetoprotein, total human chorionic gonadotropin, unconjugated estriol, and inhibin A) and triple marker test was done from 15 to 18 weeks of gestation.

Results: $12(5 \%)$ patients had positive screening test for combined screening in first trimester, $6(10.9 \%)$ patients had positive screening for quadruple test while 1 (2.85\%) patients had positive screening for triple test. Out of 19 positive screening, $16(84.21 \%)$ had their amniocentesis done for confirmation of diagnosis. In all 16 patients, chromosomal analysis was normal. Not a single patient turned out to have a baby with Down syndrome or any other aneuploidy. False positive rate for combined screening in first trimester was $5 \%$, false positive rate for quadruple test in second trimester was $10.9 \%$, false positive rate for triple marker test in second trimester was $2.85 \%$.

Conclusions: First-trimester combined screening is better than second-trimester quadruple test or triple marker test for syndrome or any other aneuploidy.
\end{abstract}

Keywords: Combined screening, Down syndrome, Quadruple screening

\section{INTRODUCTION}

The natural frequency of chromosomal abnormalities at birth, in the absence of any prenatal diagnosis, has been at 6 per 1,000 births. The aneuploides are the most frequent, with trisomy 21 (Down syndrome) the most common, with an often-quoted birth prevalence of 1 in $800 .^{1}$ The other common autosomal trisomies including trisomy 18 (Edward syndrome) and trisomy 13 (Patau syndrome) occur with 1 in 6,500 and 1 in 12,500 , respectively. ${ }^{1}$

Presently, invasive procedures remain the definitive test for fetal aneuploidies. However, these procedures themselves carry a potential fetal loss rate, though small may be unacceptable to certain women. Therefore, prenatal screening programs provide information by which couples can make appropriate informed choices 
about reproductive decisions, rather than focusing on disabilities and their eradication. ${ }^{1}$

As both amniocentesis and CVS are associated with a risk of miscarriage, these procedures are currently applied only to small group of women who are in a higher risk of having an offspring with a chromosomal defect in comparison to the general population. The aim of the currently available screening tests is to identify, with the highest sensitivity and specificity, those women who should be offered the invasive procedure. The risk for many of the chromosomal defects increases with maternal age. Additionally, because fetuses with chromosomal defects are more likely to die in utero than normal fetuses though the risk decreases with gestational age. $^{2}$

Non-invasive screening based on biochemical analysis of maternal serum or urine, or fetal ultrasound measurements, allows estimates of the risk of a pregnancy being affected. It also provides information to make decisions about definitive testing. Before screening tests, parents need to be fully informed about the risks, benefits and possible consequences of such a test. This includes subsequent choices for further tests and the implications of both false positive and false negative screening tests (i.e. invasive diagnostic testing, and the possibility that a miscarried fetus may be chromosomally normal). ${ }^{3}$

According to the American College of Obstetricians and Gynecologists, it has become routine in prenatal care to offer screening tests for neural tube defects and genetic abnormalities. There have been some changes in the method of prenatal screening. Measurement of AFP alone can detect the vast majority of neural tube defects and a small portion of trisomy 21 in patients of all ages. Adding $\mathrm{hcG}$ and unconjugated estriol to this screen increases the rate of detection of trisomies 21 and 18. Counseling patients about the risks and benefits of such screening is important. ${ }^{4}$

Down syndrome is the commonest congenital cause of mental retardation. Noninvasive screening based on biochemical analysis of maternal serum or urine, or fetal ultrasound measurements, allows estimates of the risk of a pregnancy being affected. It also provides information to guide decisions about definitive testing. ${ }^{5}$

First-trimester screening for Down's syndrome that includes ultrasound to assess nuchal translucency has become widespread since its introduction by Nicolaides and colleagues in the early 1990s. ${ }^{6}$

Second-trimester screening remains the most common method to assess the risk of Down's syndrome in the United States. ${ }^{7}$

Biochemical screening at 16-18 weeks of pregnancy can detect about $60 \%$ of pregnancies with Down's syndrome, about $90 \%$ of pregnancies with open spina bifida, and virtually all cases of anencephaly. ${ }^{8}$

With any type of testing, there is a possibility of falsepositive results and false-negative results too. A screening test result that shows there is a problem when it does not exist is called a false-positive result. A screening test result that shows there is not a problem when it exists, is called a false-negative result. Your doctor can give you information about the rates of false-positive and false-negative results for each test. ${ }^{8}$

Expected Detection Rates for Down Syndrome at a 5\% False Positive Rate Using a Variety of Combinations of Second Trimester Biochemical Markers (Cuckle). ${ }^{9}$

Nuchal scanning alone detects $62 \%$ of all Down syndrome with a false positive rate of $5.0 \%$; combined with blood testing gives corresponding values of $73 \%$ and $4.7 \% .^{10}$

Objectives of present study are to assess the effectiveness of combined ultrasound and biochemical (CUB) screening in first trimester and quadruple and triple screening in second trimester for Down syndrome and other chromosomal abnormalities in singleton pregnancies in a routine antenatal clinic and laboratory setting

\section{METHODS}

This retrospective study was conducted at Patne hospital and Maternity home, Aurangabad from January 2015 to January 2016 in 330 antenatal patients.

In recent years, antenatal screening has become one of the most routine procedure of pregnancy-follow up and the subject of hot debate in bioethics circles.

330 women whose pregnancies fell within the gestational age range of 11 to 14 weeks by ultrasound assessment were offered combined screening on the basis of measurement of nuchal translucency (NT), maternal serum free beta-human chorionic gonadotropin (Beta chg) and pregnancy-associated plasma protein A (PAPPA). NT measurements were obtained using a standardized method. Each screening marker measurement was converted to a multiple of the appropriate gestational median and a risk was derived for each marker in chromosomally abnormal and unaffected pregnancies. A combined risk of Down syndrome and of trisomy 18/13, incorporating the maternal age risk, was calculated for all women.

Patients whose screening test came as positive were offered integrated screening test. This combines the results of the first-trimester tests with those of secondtrimester screening (triple or quadruple screening). These patients were also given the option of chorionic villus biopsy directly for confirmation of diagnosis if they wish. 
If quadruple test turned out to be positive, these patients were advised amniocentesis for confirmation of diagnosis.

\section{RESULTS}

In present study, out of total 330 patients, $290(87.8 \%)$ patients were of less than 35 years while $40(12.1 \%)$ patients were above 35 years with the median age of 27 years.

Table 1: Age group.

\begin{tabular}{|lll|}
\hline Age & No. of patients & Percentage \\
\hline <35 years & 290 & 87.8 \\
\hline$>35$ years & 40 & 12.1 \\
\hline
\end{tabular}

Table 2: Period of screening.

\begin{tabular}{|lll|}
\hline Period of screening & No. of patients & Percentage \\
\hline First trimester & 240 & 72.72 \\
\hline Second trimester & 90 & 27.27 \\
\hline
\end{tabular}

In present study, out 330 patients, 240 (72.72\%) patients came in first trimester in which combined screening was done while $90(27.27 \%)$ patients came in second trimester where triple marker test or quadruple test was done.

Table 3: Type of screening.

\begin{tabular}{|lcc|}
\hline Type of screening & No. of patients & Percentage \\
\hline $\begin{array}{l}\text { Combined screening } \\
\text { (First trimester) }\end{array}$ & 240 & 72.72 \\
\hline $\begin{array}{l}\text { Triple test (Second } \\
\text { trimester) }\end{array}$ & 35 & 10.60 \\
\hline $\begin{array}{l}\text { Quadruple test (Second } \\
\text { trimester) }\end{array}$ & 55 & 16.66 \\
\hline
\end{tabular}

In present study, in $240(72.72 \%)$ patients who came for check up in first trimester, combined screening was done, in $55(16.66 \%)$ patients who reported in second trimester, quadruple test was done while in $35(10.60 \%)$ patients who reported in second trimester, triple test was done.

Table 4: Nuchal translucency.

\begin{tabular}{|lll|}
\hline Nuchal translucency & No. of patients & Percentage \\
\hline $0.5-0.9$ & 52 & 21.66 \\
\hline $1-1.5$ & 138 & 57.5 \\
\hline $1.6-2$ & 32 & 13.33 \\
\hline $2-2.5$ & 18 & 7.5 \\
\hline
\end{tabular}

Out of 240 patients in first trimester, 52 patients $(21.66 \%)$ had nuchal translucency between 0.5-0.9, 138 patients $(57.5 \%)$ had nuchal translucency between 1-1.5, 32 patients $(13.33 \%)$ had nuchal translucency between 1.6-2 and 6 patients (7.5\%) had nuchal translucency between 2-2.5. These are multiple of median (MoM) values. Not a single patient had abnormal value for normal translucency.

\section{Table 5: Positive screening.}

\begin{tabular}{|lll|}
\hline Positive screening & No. of patients & Percentage \\
\hline $\begin{array}{l}\text { Combined screening } \\
\text { (First trimester) }\end{array}$ & 12 & 5 \\
\hline $\begin{array}{l}\text { Triple test (Second } \\
\text { trimester) }\end{array}$ & 1 & 2.85 \\
\hline $\begin{array}{l}\text { Quadruple test } \\
\text { (Second trimester) }\end{array}$ & 6 & 10.9 \\
\hline
\end{tabular}

In present study, $12(5 \%)$ patients had positive screening test for combined screening in first trimester, 6 (10.9\%) patients had positive screening for quadruple test while 1 $(2.85 \%)$ patients had positive screening for triple test.

Table 6: Confirmation by amniocentesis or chorionic villus biopsy.

\begin{tabular}{|lllll|}
\hline $\begin{array}{l}\text { Confirmation by amniocentesis/Chorionic villus } \\
\text { biopsy }\end{array}$ & No. of patients & Percentage & Aneuploidy & Percentage \\
\hline Amniocentesis & 16 & 84.21 & 0 & 0 \\
\hline Chorionic villus biopsy & 0 & 0 & 0 & 0 \\
\hline Lost to follow up & 3 & 15.78 & - & - \\
\hline
\end{tabular}

In present study, out of 19 positive screening, 16 $(84.21 \%)$ had their amniocentesis done for confirmation of diagnosis, $3(15.78 \%)$ patients lost to follow up while not a single patient opted for chorionic villus biopsy. In all 16 patients, chromosomal analysis was normal. Not a single patient turned out to have a baby with Down syndrome or any other aneuploidy. False positive rate for combined screening in first trimester was 5\%, false positive rate for quadruple test in second trimester was
$10.9 \%$, false positive rate for triple marker test in second trimester was $2.85 \%$.

\section{DISCUSSION}

In present study, out of total 330 patients, $290(87.8 \%)$ patients were of less than 35 years while $40(12.1 \%)$ patients were above 35 years. Zournatzi $\mathrm{V}$ et al reported that 69 women $(12 \%)$ were 35 years old or more. ${ }^{2}$ 
In present study, out 330 patients, $240(72.72 \%)$ patients came in first trimester in which combined screening was done while $90(27.27 \%)$ patients came in second trimester out of which in $55(16.66 \%)$ patients quadruple test was done while in $35(10.60 \%)$ patients triple test was done.

In present study, not a single patient had abnormal value for normal translucency.

In present study, $12(5 \%)$ patients had positive screening test for combined screening in first trimester, $6(10.9 \%)$ patients had positive screening for quadruple test while 1 $(2.85 \%)$ patients had positive screening for triple test.

In present study, out of 19 positive screening, 16 (84.21\%) had their amniocentesis done for confirmation of diagnosis, $3(15.78 \%)$ patients lost to follow up while not a single patient opted for chorionic villus biopsy.

In all 16 patients, chromosomal analysis was normal. Not a single patient turned out to have a baby with Down syndrome or any other aneuploidy.

False positive rate for combined screening in first trimester was $5 \%$, false positive rate for quadruple test in second trimester was $10.9 \%$, false positive rate for triple marker test in second trimester was $2.85 \%$.

Alldred SK et al reported that both direct and indirect comparisons, the combined NT, PAPP-A, free $B$ hcG and maternal age test strategy showed superior diagnostic accuracy to an NT and maternal age test strategy ( $\mathrm{P}<$ $0.0001)$.

Based on the indirect comparison of all available studies for the two tests, the sensitivity ( $95 \%$ confidence interval) estimated at a 5\% FPR for the combined NT, PAPP-A, free hcG and maternal age test strategy (69 studies; $1,173,853$ fetuses including 6010 with Down's syndrome) was $87 \%$ (86 to 89 ) and for the NT and maternal age test strategy (50 studies; 530,874 fetuses including 2701 Down's syndrome pregnancies) was $71 \%$ (66 to 75$) .5$ They detect about nine out of 10 Down's affected pregnancies for a fixed 5\% FPR. Although the absence of nasal bone appeared to have a high diagnostic accuracy, only five out of 10 affected Down's pregnancies were detected at a $1 \%$ FPR. $^{3}$

First-trimester screening was performed by Fergal D et al in 38,167 patients; 117 had a fetus with Down's syndrome. At a 5 percent false positive rate, the rates of detection of Down's syndrome were as follows: with firsttrimester combined screening, 87 percent, 85 percent, and 82 percent for measurements performed at 11, 12, and 13 weeks, respectively; with second-trimester quadruple screening, 81 percent; with stepwise sequential screening, 95 percent; with serum integrated screening, 88 percent; and with fully integrated screening with first-trimester measurements performed at 11 weeks, 96 percent. $^{6}$
Wapner R. et al found that the largest U.S. study of firsttrimester screening to date, involving 8514 pregnancies, reported a 79 percent detection rate at a 5 percent false positive rate. ${ }^{11}$

Alldred SK et al found that tests involving two markers in combination with maternal age, specifically PAPP-A, free $\mathrm{hcG}$ and maternal age are significantly better than those involving single markers with and without age. They detect seven out of 10 Down's affected pregnancies for a fixed 5\% FPR. The addition of further markers (triple tests) has not been shown to be statistically superior. $^{12}$

Alldred SK et al reported that tests involving second trimester $\beta$-core fragment and estriol with maternal age are significantly more sensitive than the single marker second trimester $\beta$-core fragment and maternal age, however, there were few studies. There is a paucity of evidence available to support the use of urine testing for Down's syndrome screening in clinical practice where alternatives are available. ${ }^{13}$

Alldred SK et al reported that meta-analysis of the six most frequently evaluated test combinations showed that a test strategy involving maternal age and a combination of first trimester NT and PAPP-A, and second trimester total hcG, uE3, AFP and Inhibin A significantly outperformed other test combinations that involved only one serum marker or NT in the first trimester, detecting about nine out of every 10 Down's syndrome pregnancies at a $5 \%$ false positive rate. ${ }^{14}$

Alldred SK et al reported that meta-analysis of 12 best performing or frequently evaluated test combinations showed double and triple tests (involving AFP, uE3, total $\mathrm{hcG}$, free hcG) significantly outperform individual markers, detecting six to seven out of every 10 Down's syndrome pregnancies at a $5 \%$ false positive rate.

Tests additionally involving inhibin performed best (eight out of every 10 Down's syndrome pregnancies) but were not shown to be significantly better than standard triple tests in direct comparisons. Lower sensitivity occurred in women above 35 years of age. ${ }^{15}$

When the amniocentesis results of the patients were reviewed by Danisman $\mathrm{N}$ et al as numerically normal or abnormal; $40(2.7 \%)$ of 1456 amniocentesis procedures performed for advanced maternal age, $5(0.9 \%)$ of 531 procedures performed for an increased double-test risk and $14(1.3 \%)$ of 1095 procedures performed for an increased triple test risk were found to have chromosomal aneuploidy. ${ }^{16}$

Stenhouse EJ found that the detection rate for Down syndrome was $93 \%(14 / 15)$ at a false-positive rate of $5.9 \%$ and for all chromosome abnormalities it was $96 \%$ $(25 / 26)$ at an overall false-positive rate of $6.3 \% .^{17}$ 


\section{CONCLUSION}

Present study confirms that by first trimester screening, the number of women who have indication for invasive prenatal diagnostic procedure is significantly reduced. As a result the cost for prenatal diagnosis of the population and also the risk of iatrogenic missed miscarriages is also reduced. Finally, this screening method gives the advantage of early diagnosis.

False positive rate for combined screening in first trimester was $5 \%$, false positive rate for quadruple test in second trimester was $10.9 \%$, false positive rate for triple marker test in second trimester was $2.85 \%$.

To conclude, first-trimester combined screening is better than second-trimester quadruple or triple screening.

Funding: No funding sources Conflict of interest: None declared

Ethical approval: The study was approved by the Institutional Ethics Committee

\section{REFERENCES}

1. Spencer K. Aneuploidy screening in the first trimester. Am J Med Genet Part C Semin Med Genet. 2007;145C:18-32.

2. Zournatzi V, Daniilidis A, Karidas C, Tantanasis T, Loufopoulos AA, Tzafettas J. A prospective two years study of first trimester screening for Down Syndrome. Hippokratia. 2008 Jan;12(1):28.

3. Alldred SK, Takwoingi Y, Guo B, Pennant M, Deeks JJ, Neilson JP, Alfirevic Z. First trimester ultrasound tests alone or in combination with first trimester serum tests for Down's syndrome screening, Cochrane Database Syst Rev. 2017;3:CD012600.

4. Graves JC, Miller KE, Sellers AD. Maternal Serum Triple Analyte Screening in Pregnancy. Am Fam Physician. 2002 Mar 1;65(5):915-21.

5. Alldred SK, Deeks JJ, Guo B, Neilson JP, Alfirevic Z. Second trimester serum tests for Down's Syndrome screening. Cochrane Database Syst Rev. 2012 Jun;(6):CD009925.

6. Malone FD, Canick JA, Ball RH, Nyberg DA, Comstock $\mathrm{CH}$, Bukowski $\mathrm{R}$ et al. First-trimester or second-trimester screening, or both, for Down's Syndrome. N Engl J Med. 2005 Nov 10;353(19):2001-11.

7. Egan JF, Kaminsky LM, DeRoche ME, Barsoom MJ, Borgida AF, Benn PA. Antenatal Down syndrome screening in the United States in 2001: A survey of maternal-fetal medicine specialists. Am J Obstet Gynecol. 2002;187:1230-4.

8. ACOG. Women's health care physicians. Prenatal Genetic Screening Tests. FAQ 165. July 2017. Available at https://www.acog.org/-/media/ForPatients/faq165.pdf?dmc=1\&ts=20171212T1212581 010

9. Cuckle H. Time for total shift to first-trimester screening for Down's syndrome. The Lancet. 2001 Nov 17;358(9294):1658-9.

10. Muller F, Benattar C, Audibert F, Roussel N, Dreux $\mathrm{S}$, Cuckle H. First-trimester screening for Down syndrome in France combining fetal nuchal translucency measurement and biochemical markers. Prenat Diagn. 2003;23(10):833-6.

11. Wapner R, Thom E, Simpson JL, Pergament E, Silver R, Filkins K, et al. First-trimester screening for trisomies 21 and 18 . N Engl J Med 2003;349:1405-13.

12. Alldred SK, Takwoingi Y, Guo B, Pennant M, Deeks JJ, Neilson JP et al. First trimester serum tests for Down's syndrome screening. Cochrane Database Syst Rev. 2015 Nov;(11):CD011975.

13. Alldred SK, Guo B, Takwoingi Y, Pennant M, Wisniewski S, Deeks JJ, et al. Urine tests for Down's syndrome screening. Cochrane Database Syst Rev. 2015 Dec 10;(12):CD011984.

14. Alldred SK, Takwoingi Y, Guo B, Pennant M, Deeks JJ, Neilson JP. First and second trimester serum tests with and without first trimester ultrasound tests for Down's syndrome screening. Cochrane Database Syst Rev. 2017 Mar 15;3:CD012599.

15. Alldred SK, Deeks JJ, Guo B, Neilson JP, Alfirevic Z, Second trimester serum tests for Down's Syndrome screening. Cochrane Database Syst Rev. 2012 Jun 13;(6):CD009925.

16. Danisman N, Kahyaoglu S, Celen S, Kahyaoglu I, Candemir Z, Yesilyurt A et al. A retrospective analysis of amniocenteses performed for advanced maternal age and various other indications in Turkish women. J Maternal-Fetal Neonat Med. 2013 Feb $1 ; 26(3): 242-5$.

17. Stenhouse EJ, Crossley JA, Aitken DA, Brogan K, Cameron AD, Connor JM. First-trimester combined ultrasound and biochemical screening for Down syndrome in routine clinical practice. Prenat Diagn. 2004 Oct;24(10):774-80.

Cite this article as: Patne SS, Upadhy AJ, Shembekar SC, Shembekar CA, Upadhye JJ. Antenatal screening for aneuploidy. Int J Reprod Contracept Obstet Gynecol 2018;7:234-8. 